\title{
An integrative methodology for investigating lived experience and the psychosocial factors influencing environmental cognition and behaviour
}

\author{
Dr Nadine Andrews \\ Visiting Researcher, The Pentland Centre for Sustainability in Business Lancaster University
}

\section{INTRODUCTION}

A great deal of research and policy attention has been devoted to changing the behaviour of individuals in order to advance climate change mitigation and protection of species and habitats. However, I am interested not in behaviour change or even behaviour itself, but its underlying drivers specifically the psychosocial factors influencing individuals who are already highly motivated to behave in pro-environmental ways but don't - or at least not all the time or in all aspects of their lives. For if people with strong pro-environmental values do not enact these values consistently, what hope for changing the behaviours of people with weak commitment to these values? In this chapter I describe the approach I took to research this area, the so-called values-action gap, focussing on a study that enquired into the lived experience of individuals working to influence and improve environmental decision-making in their organisations.

Various factors have been proposed to explain incongruence between values and behaviour but the models produced are fairly limited. This is because the studies tend to be decontextualized and deal with different factors ${ }^{1}$ in an isolated rather than integrated way (Clayton et al 2016; Lülfs \& Hahn 2014). Many studies rely on theories such as the Theory of Planned Behaviour that are ill equipped to engage with the complexity of lived experience, particularly the non-rational, unconscious and context-specific dimensions (Kollmuss \& Agyeman 2002). Rather than avoid complexity, my methodology was designed to embrace it. Situating the research participants in the context of their work settings and the dominant cultural worldview of the society in which they and their organisations are embedded, I investigated psychosocial factors influencing their cognition and actions, drawing on concepts and ideas from various fields including systems thinking, social and ecopsychology, cognitive and ecolinguistics, environmental philosophy and organisational studies. This transdisciplinary methodology enabled me to identify and model the dynamics of multiple cross-level factors and produce nuanced in-depth findings. This would not have been possible with a typical survey-based approach (see Andrews 2017a, b). The factors I identified all relate directly or indirectly to psychological threat coping strategies:

- Sources of tension and threat

- Coping strategies used to negotiate these tensions

- Outcomes of coping strategies (ecologically adaptive or maladaptive implications)

- Various factors influencing the efficacy of coping strategies

- Contextual factors (organisational and socio-cultural) influencing one or other of these aspects

Following an explanation of the philosophical approach underpinning the study, I describe the procedure I adopted to generate, analyse and interpret data. I then provide a worked example of how findings from this process can be written up, generating insights into the phenomenon under study. Finally I reflect on the implications of the findings for climate and environmental action.

\footnotetext{
${ }^{1}$ Factors are typically called 'determinants' in this literature, illustrating a linear causal mode of thinking about relationships
} 
Together, these aspects offer a rich and detailed account of the methodology and demonstrate its value as an approach for engaging with the complexity of lived experience and investigating underlying drivers of environmental behaviour.

\section{PHILOSOPHICAL APPROACH}

The methodology I designed proceeds from four main premises and assumptions relating to: embodied and situated experience, unconscious processes, language as a window into conceptual systems, and my own ecological philosophy.

First, the methodology rejects the dichotomy that is often made between objectivism and subjectivism, and between our outer and inner worlds. To form this understanding I brought together three epistemological approaches: Interpretative Phenomenological Analysis, psychosocial studies, and the 'embodied realism' of cognitive linguistics.

Interpretative Phenomenological Analysis (IPA) is concerned with gaining insight into how someone experiences and makes sense of a given phenomenon in a particular context through intersubjective inquiry and analysis. IPA recognises that we cannot remove our conceptual systems from our observations of the world to find out how things 'really are' in an objective sense (Larkin, Watts \& Clifton 2006). IPA sees individuals as essentially embedded, intertwined and immersed in the world of objects and relationships, language and culture, projects and concerns (Larkin, Watts \& Clifton 2006; Smith, Flowers \& Larkin 2009). Experience is a lived process, an "unfurling of perspectives and meanings, which are unique to the person's embodied and situated relationship to the world" (Smith, Flowers \& Larkin 2009, p.21). In IPA research, there is therefore commitment to situating personal meaning in socio-cultural contexts (Eatough \& Smith 2010). More than that, it is considered a criterion for assessing quality and validity (Smith, Flowers \& Larkin 2009). This epistemological position is compatible with the epistemology of embodied realism proposed by cognitive linguists and philosophers Lakoff and Johnson. Truth, they propose, is always relative to a conceptual system, grounded in and continually tested by our ongoing embodied experiences of interacting with the world (Johnson \& Lakoff 2002; Lakoff \& Johnson 1999). For example, "a clearing is not an inherent property of that place in the woods where the trees are less dense but a property that we project onto it relative to the way we function with respect to it" (Lakoff \& Johnson 1980, p.158). According to Johnson (1987), one of the pervasive features of human experience is the experience of physical containment, which I discuss later in the example of analytic commentary. The situated aspect of experience is fundamental to the perspective of psychosocial studies, which holds that for the individual, the psychological and the social are always intertwined and cannot be meaningfully separated (Woodward 2015). Indeed, "the social unconscious operates according to principles that are similar to those of the individual unconscious" (Woodward 2015, p. 142). A focus on the unconscious is a central feature of psychosocial studies (Clarke \& Hoggett 2009).

IPA, cognitive linguistics and psychosocial studies all recognise human experience as embodied and situated, involving fundamental entanglements of psychological processes and social contextual forces. In both cognitive science and phenomenology, the physical body is regarded as integral to perception and understanding experience: it is not just as a biological object but a lived experiential structure (Lakoff \& Johnson 1980; Varela, Thompson \& Rosch 1991). This understanding about how humans create meaning forms the foundation upon which my analysis and interpretation is built. In my study, the research subjects are situated in their work settings ('person-in-organisation') and in the macro context of the dominant cultural worldview of the Western industrialised societies in which they, and their organisations, are embedded ('person-in-society'). The meaning they make emerges out of their ongoing embodied interactions with their work colleagues, organisation and 
society.

The second feature of the philosophical framework is the premise that the mind has conceptual systems that structure perception, understanding and behaviour, that this occurs in mostly unconscious processes, and that people may not therefore be consciously aware of all the processes involved in their behaviour and experience (Lakoff \& Johnson 1980; Willig \& Stainton-Rogers 2010). This is why descriptive analyses of self-report surveys have limited explanatory power. IPA permits the researcher to develop an alternative narrative of the research subject's experience, informed by extant theory. I drew upon self-determination theory (SDT; Deci \& Ryan 2000), particularly constructs of basic psychological needs, intrinsic and extrinsic goals, controlled and autonomous motivation, and vitality - the energy available to the self for action. These were themes that emerged as I analysed the data, and I found SDT useful in explaining these results. In the example of a narrative I provide later, I discuss the findings in relation to competency, autonomy and relatedness needs. Competency refers to feeling competent and effective, engaging in optimal challenges, and having an effect in the world as well as attaining valued outcomes within it. Autonomy refers to the desire to self-organise experience and behaviour, and for activity to be in accord with one's integrated sense of self and intrinsic choices. Relatedness involves seeking attachments and experiencing feelings of security, belongingness and intimacy with others. SDT proposes that these needs are drivers of behaviour and require satisfying for psychological wellbeing (Deci \& Ryan 2000).

The third main premise of the methodology is that our conceptual systems are fundamentally metaphorical in nature, and that these metaphors are expressed in language. Metaphor use is therefore not arbitrary - rather, by a person's use of particular terms, something can be inferred about how they consciously or unconsciously conceptualise their world (Deignan 2005; Lakoff \& Johnson 1980). Language both reflects and shapes the way we think, influencing how we act and relate to the world. We are continually being primed to conceptualise the world in particular ways by the dominant discourse of our social contexts, and it is this feature that makes language psychosocial (Andrews 2018). In my study I analysed the participants' accounts for frames and metaphors. This is a form of micro-discourse analysis, which means coding the text line-by-line, often word-by-word. Integrating IPA with frame and metaphor analysis enabled me to explore below the surface of the research subjects' conscious awareness.

The final element I wish to make explicit is my own ecological philosophy, which informs how I analyse and interpret data and draw conclusions about the implications of the findings for climate and environmental action. Following others (e.g. Kidner 2001; Merchant 1983; Plumwood 1993; White 1967), I regard perceptions of humans as separate from and superior to nature as a root cause of ecological crisis. This refers not just to the external world of plants and animals and natural forces but also to our inner world and the aspects of the self often associated with nature and wildness: emotions, the physical body, intuition, and the unconscious mind (Hasbach 2012; Rust 2008; Totton 2011). There are two key implications of this philosophy:

- The 'social' in psychosocial has to include relationship with other species, for the world in which we are embedded includes the other-than human natural world.

- Restoring healthy ecological balance of the planet requires restoring a healthy relationship between parts of the self and dissolving dualistic relationships between mind and body, reason and emotion. 


\section{METHODOLOGY FOR CONDUCTING FIELDWORK}

\section{Recruitment and selection of participants}

In IPA, research subjects are selected on the basis that they grant access to a particular perspective on the phenomena under study: this is known as 'purposive homogenous sampling'. In my study the phenomenon was the experience of an individual oriented to pro-environmental values working in a formal role to influence organisational practices, and the socio-cultural context for this phenomenon is industrial growth societies where nature is predominantly framed in economic terms (Andrews 2018).

I recruited five sustainability managers and a chief executive to the study. The participants had formal roles ranging from production of environmental strategies and policies, delivery of energy efficiency programmes, and conservation of habitats. The organisations were in local and regional government, social housing, credit union and health care sectors, in the UK and Canada. The participants were recruited via a variety of channels including professional networks and social media, and were selected according to three criteria to satisfy the requirement for homogeneity:

- Currently in employment with a formal role to influence environmental decision-making

- Strong pro-environmental values and goals motivating them to do their work

- Propensity and willingness to be mindful (so that they would be able to give rich accounts of their subjective experience)

IPA studies tend to focus on a small number of people (Larkin, Watts \& Clifton 2006). This is because IPA recognises the value of the single case and has an idiographic focus which means detailed examination of the research participant as a particular unique individual. This requires working with data in a highly detailed and intense way, which generates a lot of material and is very time consuming. A sample of six would render the findings invalid if it were quantitative research, and would also be considered too small in some other qualitative approaches such as grounded theory. However, in IPA the small sample does not mean that nothing meaningful can be concluded about the phenomenon - on the contrary, something very tangible and real about the subject-matter can be revealed (Larkin, Watts, \& Clifton 2006).

\section{Data collection}

The main method for collecting data in IPA is semi-structured interviews, with diaries and focus groups also used (Smith, Flowers \& Larkin 2009). The methods used in my study are shown in Figure 1 below, together with the rationale. Interviews were my main data source, and I focus on explaining the procedure for analysing this data next.

\section{Fig. 1 Data sources}

\section{Data analysis and interpretation}

IPA offers a flexible framework for analysing data. These stages are not remarkable compared to other qualitative methods: the difference is in the philosophical approach as described above and in allowing intuitive, experiential and professional knowledge to be drawn upon (Smith, Flowers \& Larkin 2009). I adapted the framework, developing a nonlinear procedure involving numerous iterative cycles as shown in Figure 2. 
Each interview was transcribed verbatim including notes of nonverbal elements such as laughter, sighs and pauses.

\section{Stage 1 - close reading of text}

Pseudonyms are assigned to each participant. Verbatim transcription of interview, number each line, several close readings of the text.

\section{Stage 2 - exploratory coding}

This is a very open process that involves asking descriptive, linguistic and conceptual questions of the text (Smith, Flowers \& Larkin 2009), as shown in Figure 3.

Fig. 3. Exploratory coding in IPA

As we can see, metaphors are classed as linguistic but in cognitive linguistics metaphors are not primarily linguistic but cognitive: they activate structures in the brain (frame-circuits) that serve as frames of reference for interpreting new information and experiences. Nevertheless, it is here that frame and metaphor analysis can be integrated into IPA to form a coherent methodology.

When we use metaphors we are thinking about one thing (the target domain) in terms of another (the source domain), and knowledge about the source domain is used in reasoning about the target domain - this knowledge is the entailment of the metaphor. For example, lets consider the phrase 'spend time'. Here, time is being conceptualised in terms of something that is 'spent'. Typically we associate spending with money: so what we know about money (the source domain) is mapped over onto how we think about time (the target domain). As money is a resource of financial value we might therefore think of time as a resource of financial value. 'Spend' is the trigger word that activates a financial transaction frame-circuit in the mind. It is these trigger words that the analyst looks out for in a text. However, as the use of frames and metaphors is often unconscious (Lakoff \& Johnson 1980), this means trigger words are not always immediately obvious so metaphors can be easily overlooked in a text. Deignan (2015) emphasises the importance of establishing consistent procedures for spotting metaphors. There is no single correct way to conduct frame and metaphor analysis. I used various established knowledge resources to guide identification of frames and metaphors and their likely entailments. Key resources included dictionaries (e.g. OED Online and Etymonline) and frame and metaphor databases (e.g. FrameNet, Metalude).

I coded the interview transcripts for various aspects of experience as shown in Figure 4 that the literature I reviewed indicated could be possible influencing factors. However, I did not know whether these would in fact show up nor how they would show up.

\section{Fig. 4. Analysis focus}

Metaphors are incomplete representations of reality that privilege one way of seeing and obscure other ways. Using abductive reasoning, the analyst asks what is being promoted and what is being hidden, and what are the implications? It is here, explicitly or implicitly, that the analyst's personal ecological philosophy has a significant influence on the conclusions that are drawn.

\section{Stage 3 - intuitive identification of key themes}


This involved listing whatever struck me as the main 'objects of concern' (Larkin, Watts \& Clifton 2006) for the participants. The intuitive insights came from noticing signals such as body language, tone of voice, hesitations, laughter and so on. I referred to these notes later in stage 6 and checked them against the results of the systematic analysis.

\section{Stage 4 - emergent coding}

I then used a more systematic, controlled and deliberate form of analysis to identify salient themes from my exploratory coding notes for each page of transcript and listed them separately. Once this was complete for each case I revisited these lists and looked for patterns, and then compiled a refined version of key themes for each case.

\section{Stage 5 - cluster emergent themes}

This stage involved systematically going through the exploratory notes and emergent coding notes in a second cycle of analysis and re-clustering of emerging themes.

\section{Stage 6 - re-cluster emergent themes into higher order themes}

I created higher order themes by re-clustering emerging themes derived from the systematic analysis of stages 4 and 5 , and compared them with key themes derived from intuitive analysis in stage 3 . This clustering process in this stage was guided by the focus of the research questions, which meant I could narrow down the themes to those that were key in the participants' experience of influencing pro-environmental decision making in the organisation. Through this process I arrived at seven higher order themes, each with a set of associated subthemes (see Andrews 2017b).

\section{Stage 7-write up case study}

I wrote a case study for each participant using content from spreadsheet, emergent coding notes, my reflexive diary and intuitive analysis notes. The format was: summary of role in organisation followed by a narrative by higher order theme that described how each theme manifested for the participant.

\section{Stage 8 - diagramming single cases}

I sketched diagrams of key features of participants' situations, as I interpreted it. Diagrams are a systems thinking tool for abstracting and representing aspects of complex situations in simplified form and showing the interconnectedness between different parts. Diagramming as a process helped me with sense making and gaining clarification about feedback loops in the situation. The diagram as an object is a visual representation of findings that can also be used in communicating the findings.

\section{Stage 9 - write case summaries}

Summaries were then created from the case studies. The format for this was a table with the themes in rows and the participant information in columns, which enabled me to easily see similarities and differences between the cases.

\section{Stage 10 - cross-case analysis}

I then performed cross-case analysis using information from the case studies and the case summary table. This involved determining where there were similarities and differences in the way that higher order themes manifested for each case, and identifying areas of convergence and divergence in exploratory themes. I checked back to the clustered themes (stage 5) for the entries for each participant to make sure nothing significant was missed. There was some refining of the phrasing of higher order and exploratory themes as a consequence of the cross-case analysis.

\section{Stage 11 - diagramming across cases}


Using an inductive process, I sketched diagrams modelling relationships between key themes based on synthesis of interpretations across cases, with reference to the diagrams produced in stage 8 (see Andrews 2017b).

\section{Stage 12 - construct themes table}

I then created table of key higher order themes and associated sub themes (emerging themes) with illustrative quotes (see Andrews 2017b).

\section{Stage 13 - frequency of frames}

I counted the frequency of particular trigger words as a way of assessing salience of associated frames. This was only intended to be indicative, as I did not capture all the possible words or phrases that could be associated with a particular frame. Frequency of use may suggest salience but it doesn't necessarily - tone of voice and body language are also cues.

\section{CONSTRUCTING A NARRATIVE}

Once the stages of analysis are complete, the final step is to write up the findings, interweaving extracts from participants' accounts with analytic commentary informed by the literature. The extracts are the phenomenological evidence grounding the interpretation (Smith, Flowers \& Larkin 2009). Typically, the findings are presented by higher order theme.

To demonstrate how a written narrative can be constructed, I will focus on the higher order theme 'Engagement with negative emotion' with subthemes 'emotion regulation' and 'reason-emotion dualism', all of which emerged in my research. Emotion is an embodied experience - it is a physiological and mental feeling state, involving physical sensations of arousal and cognitive appraisal of the cause of arousal in response to stimuli. Emotion regulation is the ability to control and productively use one's emotions, including the processes by which individuals influence which emotions they have, when they have them, and how they experience and express them. Reasonemotion dualism refers to a perceived hierarchical spilt between the rational mind and the emotional body, an idea that took hold in the Scientific Revolution and remains dominant still (Merchant 1983; Midgley 2003). Emotions are an important focus of study in climate psychology because of the powerful role that they play in directing attention and guiding behaviour (Stangor, 2010).

The narrative I present is illustrated with extracts from the interview with one of the participants, Ash, a sustainability manager at a local authority in the UK whose work involved delivering renewable energy programmes. Quotes are written in italics.

\section{Emotion regulation}

I ask Ash how he feels about the environmental situation:

Ash: Emotions I suppose when I think about it which I try and avoid think- it's rare that I- it makes me feel sad. Uh (pause)

Me: Mostly sad?

Ash: Frustrated. Not really angry, not really angry. I think I probably would have done 20 years ago. I think I just feel a sense of melancholy about it really (pause) 
Me: So what do you do with those emotions?

Ash: Um (pause) I tend not to explore them or I think I've got them in a box in my head and I carry on um being a parent and being a sustainability manager and trying to do good stuff. So and I kind of I you know in a box sitting in an attic in my mind really so I don't think its particularly helpful to explore because its kind of disabling in a way really and disheartening. So I think I put it in a box in the attic

Me: Does it still have an effect on you?

Ash: From time to time when I think about it yeah. Yeah. But it's literally in the back of my mind I suppose. So maybe it does tinge. No I'm not defeatist in my job so but yeah a sense of melancholy I suppose

In this extract Ash mentions several emotional states: sadness, frustration, 'not really angry', melancholy, disheartened, 'not defeatist'. But it seems that these emotions are being suppressed and avoided: there are descriptive self-reports of avoidance and compartmentalisation (e.g. box in the attic). This requires effort, as indicated by 'try'. Ash talks about what he thinks rather than how he feels - a type of intellectualisation that serves to distance the speaker from the felt emotion, and there are linguistic cues of pauses and not finishing sentences. Climate change and ecological crisis pose profound psychological threat (Crompton \& Kasser 2009), so these forms of emotion regulation can be interpreted as ways of defending against this threat. It would appear that for Ash, avoidant coping is both a conscious and unconscious strategy.

I will return to discuss the box in attic from a cognitive linguistics perspective shortly, but first I draw on self-determination theory to gain further insight into the threat that is triggering Ash's avoidant coping response. Interpreting the extract above through this lens reveals that there is an association in his mind between emotions of sadness and melancholy with competency, and that these emotions pose a threat to the satisfaction of his competency needs. This is indicated in several different ways:

Firstly, Ash describes feeling frustrated. Frustration is an indication of thwarted competency needs (Pryzbylski et al 2014).

Secondly, disabling. This term indicates a belief that negative emotions have a disruptive effect on effectiveness, threatening satisfaction of competency needs. This supports Macy's (1993) assertion that "we are afraid that we might break apart or get stuck in despair if we open our eyes to the dangers" (p.31).

Thirdly, disheartening. This term refers to a part of the body - the heart, often associated with emotion, spirit, desire and courage. Its use invokes not just a physical feeling in the body but also a weakening of resolve to act, a theme that recurs elsewhere in the interview (give up):

So certainly in a global context generally put myself in the pessimist camp [...] Generally I'm an optimist though, I need that otherwise I'd give up I think, so

'Giving up' is clearly an issue for the satisfaction of competency needs..

The fourth indication is the phrase not defeatist in my job. Defeat is associated with failure of action, and hence is a threat to competency. The term 'defeatist' means a person who expects or is too ready to accept failure. As shown in the quote above, Ash uses optimism as a way to keep going. Indeed, being optimistic is part of his motivational story (I need that otherwise I'd give up) but 
optimism, if unrealistic, is a form of self-deception and an ecologically maladaptive coping strategy because it allows the individual to deny the reality of the situation and avoid responding accordingly.

The motivational story is the story that Ash tells himself that provides a rationale for the work he does, justifies his experience, and motivates him to keep doing what he is doing. As Ash himself explains elsewhere in the interview he is trying to do good stuff. The story is therefore about competency but it also serves autonomy needs because the creation and maintenance of narratives such as this creates personal meaning and reconciles inconsistencies in sense of identity (Vignoles 2011), enhancing inner coherence. However, we can see from other statements Ash makes that autonomy needs are not fully satisfied by the story. Elsewhere in the interview are indications of a sense of being up against a more powerful force: he refers to the loss of natural spaces as a slow inevitable irreversible decline, and describes working with politicians to help them swim against that tide (of development) as much as they're able to. This highlights the internal tensions and contradictions that are part of his lived experience.

\section{The safety of the container}

I now return to explore the box in the attic phrase from a cognitive linguistics perspective. The 'box' into which Ash puts his emotions is an image schema of containment. This schema is often used as a conceptual domain for safety and security and implies protection of what is in the container from dangers outside, or protection of what is outside from the danger within (Johnson 1987). This is very close to the understanding of 'containment' in psychoanalytic terms (Bion 1962). The danger, as I have just established, is thwarted competency. Now that Ash has realized that he has compartmentalized his emotions about ecological crisis into a box in the attic of his mind, and is opening up this box by talking to me about these feelings, they are no longer contained and under control. I had the impression he was keen to put them back in the box as quickly as the interview allowed. This theme of safety is reflected in other statements Ash makes. Ash has explained that most of his organisation's services have some sort of environmental impact, and I ask how he feels emotionally about the impact that his organisation is having:

Ash: (silence) how do I feel about it (in quiet voice) as local government officers it's all bashed out of us in our day job because what we feel about things is completely irrelevant it's about what the business case is, and you know pragmatic

Ash conceptualises his organisation as violently hostile to emotions about ecological crisis (bashed out of $u s$ ). A reason-emotion dualism is evident: rationality (business case, pragmatic) is privileged and feelings are deemed irrelevant. Lertzman (2015, p.33) writes, "The capacity to be disturbed is linked with the capacity to be curious, and both require certain levels of containment and safety to help tolerate such experiences". For Ash, his organisation is an unsafe container for expressing feelings of sadness, melancholy and pessimism, making containment of these emotions within himself (box in the attic) the safer option. SDT recognises that social contexts can be supportive or undermining of needs satisfaction: dissonance between felt and expressed emotions is likely to be affecting Ash's sense of inner coherence.

\section{Emotion and identity}

In the extracts discussed above, experience of emotion is closely connected to sense of self. Ash separates exploration of difficult emotions about ecological crisis from his identities of being a parent and being a sustainability manager. He also identifies with being both in the pessimism camp and as an optimist, which reveals inner tensions. In the last extract he links the identity of local government officer with lack of emotion, which he associates with pragmatism and rational choice 
economics (the business case). This conceptualisation is a recurring theme in the interview. For example, Ash explains how influencing senior executives is critical to him being successful in his role, and this requires him to be seen as credible. He continues:

So early days fresh out of university very clear I'm not going to wear sandals bring lentil sandwich to work and have a beard [...] So being seen as being credible and professional [...]

Ash has deliberately chosen to suppress an identity in order to be perceived in a favourable way by those he wishes to influence - his pursuit of relatedness is in service of competency. However, the strategy doesn't work with everyone:

despite me being here for many years the Treasurer still thinks I'm basically resident Friends of the Earth [...] I could, I could call myself Ash Corporate, you know and I live at number 1 Corporate Street Corporate Town and I love doing corporate and just talk about- and he still wouldn't believe I was anything other than Friends of the Earth in residence and he's just got that despite my best efforts not to you know wear a green shirt and uh open toed sandals or try and speak with too much passion or emotion about why we need to act, which is why I find it difficult-because I so consciously shut that out.

This suppressed identity, which he refers to elsewhere in the interview as 'deep green', is associated here with passion and emotion. The effort involved in suppression is clearly articulated (despite my best efforts, I so consciously shut that out). But this passion for Ash can be counter-productive at times. He states:

sometimes particularly in meetings with senior mangers I try and rein it in

Here, emotion is conceptualised as a wild animal that needs to be brought under control. The metaphor implies a dualism between reason and emotion, and associates emotion with wild nature. This reining in of emotion is a form of containment, and it takes effort as implied with try.

\section{Implications for adaptive responses to ecological crisis}

Ash suppresses negative emotions about ecological crisis because they are perceived to be a threat to competency. Contextual forces in the form of an organisational culture of reason-emotion dualism, further discourages Ash from expressing his felt emotions. But suppression of strong emotion takes mental and physical effort, depleting vitality and impairing ability to think (Rogelberg, 2006) so there are consequences. Emotional avoidance may be appropriate in the short term for example when it is not within a person's control to change a situation in that moment (Stangor 2010) but over the longer term it is associated with poorer health (Weinstein \& Ryan 2011). More than this, emotional avoidance also has direct implications for how we respond to ecological crisis. Sadness, anger, melancholy etc. are sources of information. Ignoring these cues protects us from having to make radical changes or take significant climate and environmental action. As Rust (2008, p.160) says, "when we block out our feelings we lose touch with the urgency of the crisis". In the analysis example I have presented, we can see that emotional avoidance is a coping strategy that is an underlying driver of behaviour and a factor influencing the relationship between proenvironmental values and action. 


\section{CONCLUSION}

In this chapter I have described a methodology for investigating conscious and unconscious processes in lived experience. The study for which the methodology was designed aimed to gain insight into psychosocial factors affecting enactment of pro-environmental values by individuals in their organisations. I took a systemic and integrative approach to investigating these factors, through a phenomenological enquiry that situated the research subjects in the dynamics of their work settings and the socio-cultural context in which they and their organisations are embedded. The methodology is transdisciplinary, integrating Interpretative Phenomenological Analysis with frame and metaphor analysis, and draws upon theories of psychological threat and coping, needs, emotion and embodied cognition.

I have provided an example of analytic commentary to demonstrate how the analysis can be written up in a nuanced and in-depth way. The analysis and interpretation includes but also goes beyond description of how the research subject makes meaning of his experience of emotion. It offers an alternative narrative that explains his emotion regulation in terms of psychological threat and needs satisfaction, enriching our understanding of the experience, conceptualisation and expression of emotions. These insights are important to climate psychology because of the powerful role that emotions play in environmental decision-making and behaviour.

Frame and metaphor analysis uses abductive reasoning, and the analyst has to be extra careful in checking their own biases when drawing inferences from the data. With the integrated methodology presented here, there is perhaps higher potential for idiosyncratic interpretations, making credibility checks a critical feature of the research design. This was the purpose of the final debrief that I held with research participants, where I shared the key findings and sought their feedback. The interpretations offered here are just one possible reading and are certainly not a claim of objective truth. Other theories and approaches would necessarily lead to different findings and interpretations.

There is value in an integrated phenomenological and cognitive linguistics approach to investigate underlying drivers of behaviour, and I hope that other researchers will be inspired to adopt similar approaches. Transdisciplinary research that can engage with the complexity of human-nature relationship in new and creative ways is desperately needed.

\section{References}

Andrews, N. (2017a). Psychosocial factors affecting enactment of pro-environmental values by individuals in their work to influence organizational practices. Doctoral thesis. Lancaster University, Lancaster UK.

Andrews, N. (2017b). Psychosocial factors influencing the experience of sustainability professionals. Sustainability Accounting, Management and Policy Journal, 8(4), 445-469.

Andrews, N. (2018). How cognitive frames about nature may affect felt sense of nature connectedness. Ecopsychology Journal, 10(1)

Bion, W. (1962) Learning From Experience. London: Heinemann

Clarke S., \& Hoggett P. (2009). Researching beneath the surface: psycho-social research methods in practice. London: Karnac.

Clayton, S., Swim, J., Steg, J., Devine-Wright, P., Bonnes, M., \& Whitmarsh, L. (2016). Expanding the Role for Psychology in Addressing Environmental Challenges. American Psychologist, 71(3), 199-215. 
Crompton, T. \& Kasser, T. (2009). Meeting environmental challenges: the role of human identity. Godalming UK: WWF-UK.

Deci, E.L., \& Ryan R.M. (2000). The "what" and "why" of goal pursuits: Human needs and the selfdetermination of behaviour. Psychological Inquiry, 11, 227-268

Deci, E.L, Ryan, R.M., Schultz, P.P. \& Niemiec, C.P. (2015). Being aware and functioning fully. In: K.W. Brown, J.D. Creswell \& R.M. Ryan, (Eds.), Handbook of Mindfulness; theory, research and practice (pp. 112-129). New York: The Guilford Press.

Deignan, A. (2005). Metaphor and Corpus Linguistics. Amsterdam: John Benjamins.

Eatough, V., \& Smith, J. (2010). Interpretative phenomenological analysis. In: C. Willig \& W. Stainton-Rogers, (Eds.), The SAGE handbook of qualitative research in psychology (pp. 179-195). London: Sage Publications.

Hasbach, P.H. (2012). Ecotherapy. In: P.H. Kahn \& P.H. Hasbach, (Eds.), Ecopsychology: Science, totems, and the technological species (pp. 115-140). Cambridge MA: MIT Press.

Johnson, M. (1987) The body in the mind. Chicago: University of Chicago Press.

Johnson, M., \& Lakoff, G. (2002). Why cognitive linguistics requires embodied realism. Cognitive Linguistics, 13(3), 245-263.

Kidner D.W. (2001). Nature and psyche: radical environmentalism and the politics of subjectivity. Albany: State University of New York Press.

Kollmuss, A., \& Agyeman, J. (2002). Mind the gap: why do people act environmentally and what are the barriers to pro-environmental behaviour? Environmental Education Research, 8, 239-26o.

Lakoff, G., \& Johnson, M. (1980). Metaphors We Live By. Chicago: University of Chicago Press.

Lakoff, G. \& Johnson M. (1999). Philosophy In The Flesh: The Embodied Mind and Its Challenge to Western Thought. Basic Books.

Larkin M., Watts, S. \& Clifton, E. (2006). Giving voice and making sense in interpretative phenomenological analysis. Qualitative Research in Psychology, 3, 102-120.

Lertzman, R. (2015). Environmental melancholia: psychoanalytic dimensions of engagement. East Sussex: Routledge.

Lülfs, R. \& Hahn, R. (2014). Sustainable behaviour in the business sphere: a comprehensive overview of the explanatory power of psychological models. Organization \& Environment, 27, 43-64

Macy, J. (1993). World as Lover, World as Self. Berkeley: Parallax Press.

Merchant, C. (1983). The Death of Nature. San Francisco: Harper \& Row.

Meyerson, D.E., \& Scully, M.A. (1995). Tempered radicalism and the politics of ambivalence and change. Organization Science, 6, 585-600.

Midgley, M. (2003). Myths We Live By. London and New York: Routledge.

Plumwood, V. (1993). Feminism and the mastery of nature. London: Routledge.

Pryzbylski A.K., Deci, E.L., Rigby, C.S. \& Ryan, R.M. (2014). Competence-impeding electronic games and players' aggressive feelings, thoughts, and behaviors. Journal of Personality and Social Psychology, 106, 441-457.

Rogelberg, S.G. (Ed.) (2006). Encyclopedia of Industrial and Organizational Psychology. Sage Publications, London UK.

Rust, M. (2008). Climate on the couch. Psychotherapy and Politics International, 6, 157-170. 
Ryan, R.M. et al. (2010). Vitalizing effects of being outdoors and in nature. Journal of Environmental Psychology, 30, 159-168.

Smith, J., Flowers, P. \& Larkin, M. (2009). Interpretative Phenomenological Analysis: theory, method and research. London: Sage.

Stangor C. (2010). Introduction to psychology. $1^{\text {st }}$ Canadian edition.

https://opentextbc.ca/introductiontopsychology/ Accessed 18 July 2018.

Thomas D.R. (2006). A general inductive approach for analyzing qualitative evaluation data.

American Journal of Evaluation, 27, 237-46.

Totton, N. (2011). Wild Therapy: undomesticating inner and outer worlds. Ross-on-Wye: PCCS Books.

Varela, F., Thompson, E. \& Rosch, E. (1993). The Embodied Mind. MIT Press.

Vignoles, V.L. (2011). Identity motives. In: S.J. Schwartz, , K. Luyckx, \& V.L. Vignoles, (Eds.), Handbook of Identity Theory and Research. Springer.

Weinstein, N. \& Ryan, R.M. (2011). A self-determination theory approach to understanding stress incursion and responses. Stress and Health, 27(1), 4-17.

Weintrobe S. (Ed.) (2013). Engaging With Climate Change: psychoanalytic and interdisciplinary perspectives. Hove, UK: Routledge.

White, L. (1967). The historical roots of our ecological crisis. Science, 155 (3767), 1203-1207.

Willig, C., \& Stainton-Rogers, W. (2010). Introduction. In: C. Willig, \& W. Stainton-Rogers, (Eds.), The SAGE handbook of qualitative research in psychology (p. 1-13). London: SAGE Publications Ltd.

Woodward, K. (2015). Psychosocial studies: an introduction. Abingdon: Taylor \& Francis. 